\title{
EXPOSING BEST PRACTICES THROUGH NARRATIVE: The ERP Example
}

\author{
Erica L. Wagner \\ Cornell University \\ Robert D. Galliers \\ Bentley College \\ Susan V. Scott \\ London School of Economics
}

\begin{abstract}
The phrase best practice has entered into common parlance in contemporary business discourse, yet recent research has shown that the construction of industry standards and their inscription into software packages is not straightforward. Organizations increasingly find they are bound to accept project outcomes that have emerged as a consequence of negotiations between an installed base of consultancy or software vendor solutions and local context. We adopt a narrative approach to analyze the negotiation of a best practice design during the implementation of an ERP system. Having adopted the position that the IT artifact is part of an ensemble of networked agencies that shift over time, we then use an actor-network perspective to trace the different sources, agencies, and affects of inscription during the ERP project. Doing so highlights the politics involved in localizing an IT artifact and the issues raised when software vendors and sector specific partners collaborate with the intention of manufacturing a commercially viable ERP package intended to represent the embodiment of best practice. The paper contributes to IS research discourse by demonstrating the application of narrative analysis in longitudinal interpretive field studies.
\end{abstract}

Keywords: Best practice, ERP systems, appropriation, implementation, actor network theory, narrative analysis, interpretive research, longitudinal research. 


\section{INTRODUCTION}

Enterprise resource planning (ERP) systems aim to standardize business processes and to integrate functions, data, and organizational structures through software reference models (Kumar and van Hillegersberg 2000). Vendors frequently claim that ERP systems are inscribed with state-of-the-art best practices for a particular industry, saving organizations from reinventing the wheel and perpetuating local business practice anomalies (Cortada 1998; Davenport 2000). Recent research has critically evaluated the notion of so-called best practices, raising awareness that these benchmarks are driven by consultants and software vendors seeking economies of scale for their products and services (Newell et al. 2000; Sawyer 2001; Walsham 2001). Swan et al. (1999, p. 284) argue that IS best practices are "illusory and potentially disruptive because of the different interests between technology suppliers and IS adopters."

In this paper we build upon this perspective using a distinctive approach that combines actor-network theory (Callon 1986; Latour 1987) with narrative research methods (Wagner 2003) in order to analyze the inscription of priorities during the configuration of best practice software packages as part of a large-scale IS implementation. Using empirical material gathered during a longitudinal study we illustrate the tensions that are generated between local working patterns and the technological constraints of the system (Hanseth and Braa 1998; Walsham and Sahay 1999). We develop this further by examining the way in which the ERP system is made to work despite significant mismatches between local context and best practice.

This research extends and develops existing critiques that have focused upon the way in which best practice relates to business process reengineering (Newell et al. 2000), interfirm knowledge transfer (Timbrell et al. 2001), benchmarking IT practices (Cragg 2002), and evidence-based information systems (Atkins and Louw 2000). Our particular contribution centers upon the use of ANT and narrative approaches to trace the ebb and flow of different sources, agencies, and affects of inscription during a multiyear ERP project. In other words, during the negotiations that surround the efforts to construct an industry gold standard, whose interests are left behind and whose go forward? What can we learn about the status, nature, and plausibility of best practice software designs by studying a rich ERP case study?

The case study provides particular interest as it documents the attempt by a leading United States university to design, in collaboration with an international software vendor, an ERP product intended to represent the embodiment of best practice in academic administration. The empirical material presented provides a window into the local processes involved in constructing products that are subsequently sold to an international market as a global standard. Told over time as the phases of change unfolded, these narratives give insights into why organizations buy into the best practice mentality, how different coalitions form to manage the implications of modernization, and the effort required to make best practice ERP software packages work.

\section{METHODOLOGY AND CONCEPTUAL SCHEME}

We use a broadly interpretive research approach (Walsham 1993) in which multiple perspectives and articulations of interests are sought out as the basis of analysis. A 
longitudinal case study was conducted from June 1999 to August 2000 with an Ivy League university (Ivy) and their ERP development partner, a multinational software vendor (Vision). Five field site visits were made to Ivy (each lasting an average of eight weeks) in order to conduct interviews with project members and Ivy employees. These visits resulted in 137 interviews $^{1}$ with 53 project stakeholders (see Table 1).

Preparatory background visits to Ivy during research design inspired the selection of a narrative approach. The lead researcher was struck by the insistence of those she met that the ERP project had been "talked up" so much it would not be allowed to fail. This intriguing insight led her to craft a methodology that captured events and opinions as they unfolded over time. It was imperative to document these in a timely fashion, charting their progress and analyzing the process by which they are effectively buried.

In narrative interviews, participants are asked to describe current experiences, with the researcher listening for convincing explanations of "why things are the way they are" (Bruner 1990). The researcher is not expecting to access the truth; instead, the narrative is treated as a performance in which events are retold in a particular order and for particular effect. The narratives gathered are interpreted as "artifactual representations of the intentions, actions or goals of actors situated in time" (Czarniawska 1998). The task is to interpret these artifacts in order to come to a finer reading of the situation and provide plausible theoretical explanations (Bruner 1990).

When handling narrative data it is important to recognize that narratives move on and interviewees reframe stories in subsequent accounts, black- boxing issues that used to be open controversies, repositioning themselves, redefining priorities. Rather than seeing this as a problem, changing narratives can form a point of analytical leverage. Here, the narrative approach enabled us to reveal insights into processes of negotiation over time.

Table 1. Interviews Conducted at Ivy

\begin{tabular}{|c|l|c|c|c|c|}
\hline \multirow{2}{*}{$\begin{array}{c}\text { Actors } \\
\text { Interviewed }\end{array}$} & Organizational Role & $\begin{array}{c}\text { Summer } \\
\mathbf{9 9}\end{array}$ & $\begin{array}{c}\text { Winter } \\
\mathbf{9 9}\end{array}$ & $\begin{array}{c}\text { Spring } \\
\mathbf{0 0}\end{array}$ & $\begin{array}{c}\text { Summer } \\
\mathbf{0 0}\end{array}$ \\
\hline 6 & $\begin{array}{l}\text { Central administrative } \\
\text { leader }\end{array}$ & 4 & 2 & 7 & 3 \\
\hline 13 & End-user & 6 & 8 & 12 & 5 \\
\hline 8 & Faculty & 0 & 1 & 7 & 3 \\
\hline 6 & Project management & 5 & 5 & 7 & 5 \\
\hline 20 & Project team member & 19 & 11 & 15 & 12 \\
\hline & $\begin{array}{l}\text { Total interviews by } \\
\text { phase }\end{array}$ & 34 & 27 & 48 & 28 \\
\hline 53 & $\leftarrow$ Actors & Totals & \multicolumn{2}{|c|}{ Interviews $\rightarrow$} & 137 \\
\hline
\end{tabular}

${ }^{1}$ See Wagner (2003) for a detailed discussion of narrative research and methodological approaches. 
After the first round of interviews, it became apparent that the issues and actors referred to in the narrative accounts clustered around the negotiations taking place about ERP project priorities. These, in turn, highlighted multiple interpretations of best practice reflecting the embeddedness of actors in context and vested interests. Listening to interview tapes, and combing transcripts for controversial actors as well as organizational allies, helped in following the action. While individual accounts of change do not in themselves create change, woven into these individual narratives are connections and politics that highlight the basis for coordination (Bruner 1990). By tracing the path of these connections, insights emerge as the constitution of issues and processes of negotiation. This approach to research can only ever by partial; however, a fieldwork journal and color coding of charts were used in order to enhance rigor. The process is rarely neat, since participants often interweave their personal narratives with references to collective, institutional, international, or cultural issues.

The approach challenges the convention of selecting a discrete unit of analysis. Traditional sociological analysis has a tendency to separate macro, meso, and micro levels of focus. Instead, a narrative approach allows scope for global, collective, and local negotiations to be considered simultaneously. In order to analyze such data it is necessary to find a conceptual scheme that supports this multilevel approach.

It is for this reason that we maintain narrative and ANT work sympathetically together. Latour (1999) has argued that the foundations of ANT are based upon tracing relationships between actors rather than on their relative size. For example, when studying business practice within a prestigious university, actor narratives should determine the action and transport the research focus. United States accounting trends become actors only when and if interviewees define them as such. Such trends are not interpreted as the macro-level structure that influences local action but rather as a resource employed by delegate actors to translate interests. The criteria for their inclusion became a reference in narrative data concerning their involvement in Ivy's ERP initiative.

Through attention to language, the strength of ties within and between networks becomes apparent. Narrative is particularly helpful for studying the constitution of agency and the production of networks because individual stories of negotiation speak on behalf of a network of interests. An individual's account of change when viewed from an actor-network perspective is interpreted as a delegate or spokesperson for a particular set of interests.

ANT provides yet another point of analytical purchase for narrative data. When IT is involved in a situation to which the narrative refers, it is given status as an actor. A stream of actor-network studies exist that focus on conceptualizing ERP as an organizational actor with interests that actively influence project negotiations (cf. Hanseth and Braa 1998, 1999; Scott and Wagner 2003). ANT does not define agency as a solely human characteristic, instead asking that researchers follow the action as it unfolds without specifying in advance who or what participates in negotiations. Although controversial (cf. Collins and Yearley 1992), ANT's broad constitution of agency can provide an opportunity to consider on whose behalf delegate actors work and what interests they inscribe (cf. Law 1999).

Since a major aim of IS research is to theorize the agency and role of IT within contemporary society (Orlikowski and Iacono 2001), our goal was to "give voice" to 
nonhuman actors. These narratives reflect particular values and politics and represent an epistemological ordering (Scott 2000) that can influence the future of work practices. In this study, when a reference was made to a group, or a cause or action was attributed to nonhumans such as the ERP system itself, a delegate was interviewed and technical documentation reviewed.

The combination of ANT and narrative approaches creates a theoretical context in which to question how some stories become more accepted than others. Why do particular actors, issues, or events fade away, no longer making significant appearances in the narrative data gathered, while others continue to dominate? Latour (1999, p. 307) calls this latter state of achievement a "matter of fact—something so ingratiated within a community...that its presence is indisputable and obvious." By analyzing narrative data over time using ANT, we come to appreciate the effort that this achievement takes in a community. ANT is a theoretical apparatus for understanding change and order, highlighting the processes of negotiation through which interests become inscribed and translated. For a particular storyline to rise to prominence, rival sets of interests have to be dismantled.

Inscription of interests implies a prior process of negotiation about "what will be carried forward...and what will be left behind to make room for the new" (Latour 1999, p. 71). This provides insights into what it means to be connected or disconnected from a socio-technical ensemble. The successive inscription of interests into material form provides us with a partial history of what circulated within an ontological network. However, if we follow the processes of inscription, we can capture the properties that are gained as well as those that are lost in each stage of transformation (ibid). Inscription marks the achievement of order in the translation of interests and heralds the formation of a new network configuration where the present is similar but different from the past. These translations are made more permanent and tangible over time as they are inscribed into a more material form (Akrich and Latour 1992). In the context of an ERP system, this can create an installed base (Hanseth 2000) that may resist change and contribute to the shaping of an organizational future that favors a particular worldview.

\section{ANALYZING THE NEGOTIATION OF BEST PRACTICE AT IVY}

\subsection{Negotiating Buy-In: Forming the Best Practice Coalition}

To set the scene for this empirical material we evoke pressing concerns characterizing use of IT in higher education institutions in the 1990s. Y2K inspired the replacement of many legacy systems and higher education management were aware of the need to show compliance with increasingly keen risk management regulations. These conditions created a market for ERP and a race among IT vendors for association with a brand claim to best practice. Vision was interested in developing a strategic partnership with Ivy to create a standard ERP package that would be sold internationally. To achieve this Vision acquired contextual expertise that would help define the patterns of use associated with university best practices. These patterns would be designed into ERP 
modules and then connected to Vision's preexisting government package to create another industry-specific product.

But, Ivy end-users expressed resistance to the system. Their stories reveal both the negotiations that preceded the design of best practices and how such decisions excluded alternative practices.

When this project started they told us that it was going to make our lives easier. At least we expected [it] to have the grant accounting system that has worked for many years...why break something that [isn't] broken?....[The vice president] let the bean counters run wild so the next thing you know they've designed grant accounting based on some textbook budgeting trend. They take nearly 30 percent of my grant money in indirect costs so they can administer my money and then they have the balls to create a system that doesn't give me any of the answers I need to manage my projects. (Faculty Member)

Faculty felt the project team were purposefully designing their preferences out of the ERP system in order to assert central control over faculty research accounting. The negotiations that preceded this can be illuminated through the power brokering of Ivy's budget director who had the ear of the vice president for finance-a respected leader who championed the Vision partnership. The director used this relationship to legitimize his corporate accounting perspectives. He argued that faculty should be required to manage their research projects as professional businesses.

Our value here is the creation and transmission of knowledge. When I ran my own business, my value was making the most money...I don't find the tools to get to those values very different...I would say that the mentality that we've had for managing is primitive to say the least.... We want to move people toward a [time-phased] management model.

The notion that grant accounting practices were antiquated successfully enrolled project team members who agreed to design the ERP system around perceived corporate best practices. The budget director's narrative is interpreted as a delegate or spokesperson for corporate accounting interests. His vision was repeated almost verbatim within the narratives of project team actors. In this way the team are expressing their enrolment within the director's network, connecting themselves to a powerful group of corporate accounting interests. Further, the director's network gained momentum through the inscription of interests into material objects such as time-phased budgeting and the financial management module. These nonhuman actors are delegates that work on the director's behalf in order to translate conflicting network interests, thereby perpetuating the stability of a corporate accounting vision.

When the ERP system went live, the Ivy community was presented with a concept that changed previous methods, processes, and motivations for grant accounting in ways that Ivy staff found difficult to manage. Despite these tensions, this product design became represented by Vision as the embodiment of university best practices. Yet as a faculty advocate said, "no university... we know of is using the [time-phased] method as implemented in the [Ivy-Vision] ERP." 
Faculty interpreted the Ivy-Vision design as representing more than an administrative change.

\begin{abstract}
By making a decision to go with [Vision]...senior management...was making it impossible for [Ivy] to continue doing business in fragmented silos. Like it or not, you've got to work with a new way of accounting. It's integrated-it's slower, it's apain in the ass. And the faculty who used to do it the old way for years decide it's absolutely terrible - they don't want to do it [because] it's not [Ivy's] way....You don't like it? You're out of the...picture. If you're more inclined to accept the changes...you're in the narrow universe of people we'll work to have consensus with.
\end{abstract}

This quote implies that the practices inscribed into the ERP system by a small group of powerful actors surfaced as the best way of working - an indisputable organizational reality. Potential Vision clients see the Ivy-Vision system as the gold standard for university administration while Ivy is still radically customizing its business processes, organizational structure, and ERP technology because of the recalcitrance of end-users to accept Vision's best practice design. We now turn our focus to these challenges.

\title{
3.2 Translating the Best Practice ERP System
}

Faculty members and their staff were frustrated that a business-oriented rationale had been prescribed by the project team without consultation. They felt insulted that their grant accounting functionality was not prioritized in the best practice design.

The best practice product aimed to be an achievement of order. However, the emergence of Excel-based shadow systems illustrated that creating a standard ERP package is not the same as achieving user acceptance of that standard. Supporting the appropriation of an ERP system for use by Ivy actors required more and more resources. The project team was forced to reintroduce aspects of the legacy systems. The post-installation customization efforts helped to temper the rigid best practice design.

In response to faculty pressure, the project team agreed on three courses of action. First, they would leave the mainframe legacy accounting system running until ERP functionality was created. Second, they would meet the faculty's requirements by designing legacy "financial commitments" into the system. Third, two interim transaction support centers (TSC) would be staffed with clerical workers acting as boundary objects (Star and Griesemer 1989) between the ERP system and Distributed managers.

A customized legacy-ERP application was "bolted" onto the ERP accounting module. The project team presented this as a user-friendly solution with a Web-based interface and promptly turned off the mainframe legacy system. The bolt-on was meant to further enroll recalcitrant faculty by keeping administrative work activities within the boundaries of the system. Instead, business managers used the bolt-on to shift boundaries away from the project team toward their own needs. The bolt-on converted raw data into familiar financial commitments through ERP-based software code thus freeing users 
from the need to become familiar with the ERP. Staff would then import these data into Excel to create their "old-world" faculty reports on commitments.

This translation process was more convoluted and time-consuming than the legacy environment, but was preferred by administrators who needed control of financial commitments. It required them to flip back and forth between different definitions of best practice in the management of faculty grants. The bolt-on fused two design rationales (best practice and legacy), by acting as a point of translation for the administrators. Notwithstanding, the administrators themselves were required to act as "marginal people" (Bowker and Star 1999) who sat at the crossroads between faculty expectations and managerial imperatives.

As the administrators began to develop trust in the bolt-on and the support centers, they began asking TSC staff to do their reconciliations. This was not well received by the project team for three reasons. First, central managers wanted to discourage detailed monthly reconciliations by clerical staff in favor of a conceptual shift toward timephased budgeting. Second, they wanted the centers and the bolt-on to be viewed as temporary, capable of being disbanded in favor of full migration to the ERP environment. However, faculty and administrators commended the transaction support centers, and their responsibilities are increasing. As one TSC manager explains their role,

we're supposed to be gone soon but we've been able to do a lot of trouble shooting... we get a lot of phone calls. We help people who're still using... Excel.. .and the bolt-on but also have to understand the [Vision] system. In the beginning it was extremely stressful [because] all these administrators worked very hard and they [weren't] getting anywhere...we bailed them out...people were...stressed to the point of tears.... So we let them keep their models and we say don't worry, give it to us, we'll get it into [the system].

Administrators were becoming further entrenched in their legacy accounting practices because they were able to maintain their preferred work practices when communicating with the TSC. Center staff would then be responsible for translating this language into the ERP system. This was troublesome for the project team because departmental users were expressing a backlash against their attempt to shift the translation effort. Third, the drive to rationalize administrative paperwork and accompanying work processes was diminished because each administrator could interact in their own way with center staff, based on the personal relationships that were developing. Together, these three concerns indicate the power of the supposedly silenced to challenge the achievement of order within Ivy. The centers still exist at the time of writing, over three years after the installation of the best practice ERP design. By insisting on and negotiating flexibility in the creation of these translation points, the faculty were able to gain concessions by shaping the process through which they would interact with the best practice system. The following, from a project leader, recounts a story signifying the complexity of enrolling faculty into the time-phased approach.

We're trying to make things as simple and straightforward as possible and we've failed miserably so far.... The grant reports are the best example of the 
difficulties we have....The Economics professor that used to be Provost...called the [current] Provost really angry because he couldn't read his grant report. The [financial controller] sat down with him and every concept he was asking for was on that report. But he couldn't see it and his business manager couldn't explain it so she's been making him Excel reports....This guy's smart! He knows what he's doing and he can't even read the report, and I thought that was pretty telling. So now faculty aren't using the ERP and what we have...is a very expensive data repository, and still a lot of silos of micro-computing.

By obscuring familiar, valued legacy concepts, the design failed to translate faculty interests. The system that was being naturalized within Ivy was a hybrid whose design fused together best practices with the values and politics of multiple networks and blurred the boundaries of administrative practice.

Ivy's locally accepted interpretation of Visions' best practice standard will almost certainly include a potentially incompatible set of constituent elements including Excel software, the bolt-on, interim support centers, and accompanying business processes. We consider the implications of this hybrid design next.

\subsection{Redefining Best Practice and Achieving Order}

So, Ivy worked to achieve order through coalition building and translating between espoused best practice and the working needs of those hosting it. For example, the multiple translations that occurred during the grant accounting controversy illustrate how compromise tends to provide diverse groups enough resources to make the system work by repairing conflict and building a good enough solution to translate the interests of previously disparate networks. The moments of enrolment and translation emphasize the inclusion of heterogeneous concepts of work within artifacts expected to be used in daily administrative routines (Scott and Wagner 2003).

The ERP system's reliance on the bolt-on reveals that multiple, often conflicting perspectives can come to reside within a single technological artifact, thereby integrating diverse organizational groups. The system that becomes appropriated by Ivy will result from negotiations between different groups. Similarly, it may be surmised that this system will continue to evolve over time as interests change and organizational goals shift.

Ivy actors updated the University's grand narrative to incorporate the uncertainty of contemporary administrative practice. At the same time this contemporary narrative brings forward time-honored traditions for which actors negotiated a place within Ivy's future operating environment. In so doing, far more actors must be enrolled into the story because the narrative is sympathetic to multiple perspectives.

Starting over was not an option apparently so we still don't have either system fully in place....[Administrators] clearly understand that the faculty are their customers, and try to provide...services they most need and value. Why has Central management become invested in changing...from a tried-and-true system...to one that hasn't been tested....and is less efficient and useful? My guess is that there's too much water under the bridge to go back-which is why 
we're building our own. This is the most fascinating part of the whole story! I wish I knew how it turns out, or even how to turn it around! (Medical School Manager)

As Latour (1999) notes, being able to sustain order over time requires a great deal of resources. The more diffuse the network ensemble (from project team to University community), the more difficult it is to retain order because heterogeneity reigns (faculty interests will differ from those administrative leaders) and there will always be "a bombardment of offers" where alternative ontological networks are vying for dominance.

Although an orthodox ERP system might never be the best practice at Ivy, the evidence suggests that the design of multiple perspectives into systems is a resilient and ingenious act of will. As expressed by the newly appointed director of Integrated Administrative Systems.

So what's the good stuff?...One is that I find that the people who were... actually involved in project implementation-in spite of all the arguments...are a pretty cohesive and dedicated group. They understand how things work and they try very hard...everyone wants to do their best...but what we think is best differs. We'll make it work but... there's a tendency to...fall back to the old way of thinking...So it's...a balancing act... you can't keep...all these independently minded ducks in a row, especially when those ducks are Nobel Prize winning faculty.

Above all, Ivy's project narrative has been one of making it work: prioritizing workable solutions over ideology and purported best practice. Unlike previous studies that have depicted powerful ERP systems forcing change on a victimized organization, our analysis reveals greater potential symmetry in the negotiation between human and nonhuman actors. Vision's strategy of selling Ivy's practices as a solution for their higher education market assumes a high-degree of homogeneity between research universities and community colleges. This has implications not only for North American institutions whose activities are quite diverse, but also for universities world-wide where the "commercialization of education" (Noble 1998) is a far less familiar concept. Notwithstanding, the Ivy-Vision alliance helped create the vendor's higher education industry solution, which is being marketed internationally as best practice- despite Ivy's adaptation of it.

\subsection{Reflections}

The findings open a Pandora's box illustrating the politics of creating such standards. First, the notion of inscribed best practices can impact local acceptance and use of standard software products. Second, the term best practice does not imply majority rule. IT-based best practices are constructed by those actors who are able to materialize preferred patterns of use. Within Ivy, a small group of actors controlled this process and drove the design decisions related to what was classified as best. Third, 
while literature exists on best practices, the process of arriving at them is not considered to any extent. Instead, these actions are black-boxed and assumed. We argue that this is storing up trouble for software companies and the reputation of packaged software (ERP)/ outsourcing strategies. If Ivy was unable to use the best practice solution it helped design, how can other institutions be expected to find success by implementing the higher education solution propagated on the Vision web site?

Fourth, there is a relationship between best practices and the bandwagon effect (Fujimura 1996), where the latter refers to the extent to which one is influenced by what others have done. Perpetuating the ERP bandwagon (Kremers and van Dissel 2000; Kumar and van Hillegersberg 2000) into the $21^{\text {st }}$ century is in part about selling the best practice ideal-something that seems to require the collusion of client organizations, management consultants, and software vendors. For example, Ivy currently finds itself between a rock and a hard place in terms of communicating their ERP experiences. Any discussion related to the recalcitrance of faculty and end-users could influence the sales of the Vision product. Ivy fears that low sales would limit Vision's future investment in the product. Since Ivy is contractually bound to periodic upgrades and needs in-house Vision programming expertise, they have chosen to publicly perpetuate the myth of their ERP system as the higher education gold standard.

We've a vested interest in getting [Vision] to increase investment in the higher education ERP but we're also interested in an honest dialogue with universities. So how do we encourage other universities to go with [Vision] when the process has been so difficult? We think that by continuing to be development partners...we'll have a lot of influence over how the product does develop in the long run and it will get easier for other universities. Ultimately, the bigger [Vision's] higher education business, the better the applications will end up being...because they will invest more in our [sector]. (Project Team Leader)

We argue that inscription of work practices into ERP technology necessarily involves leaving behind historically valued activities judged by a small group of stakeholders to be less than best for common industry needs. The irony is that Ivy was itself unable to enroll its end-user community into adopting the standard package. Instead, obtaining local acceptance and use of the package has required the project team to revisit the pre-ERP environment to create a more inclusive definition of local practices. This does not simply mean that more legacy practices are incorporated into the ERP system, but that in creating a working system, Ivy wove together historically valued practices with the ERP design and created a system that is best for their local context. This leads us to reflect upon the hollowness of best practice claims and to consider what we mean when we talk about efficiency gains in reusing software designs.

\section{DISCUSSION}

This study has shown that the challenge of software appropriation is to both understand the negotiations involved in making a system work and to enroll enough actors at the right time(s) to create a critical mass of users who accept the system and will then 
mobilize others to do so. Particular attention has been paid to the translation ofdifferent interests into technology-based practices. Through an actor-network perspective we understand the temporary and partial nature of these inscribed standards. Critical reflection of the political agendas that inform and often drive design decisions help produce a historically situated account of how things come to be defined as best. The challenge for IS scholars is to reassess our understanding of when to involve actors in making IT work, and focus research attention on the use of technology in practice.

In this section we begin by discussing the notion of involvement during large software projects. We argue that making a system work requires appropriation which can only result from knowing who and what to involve in the initiative, and also when to leverage that knowledge.

\subsection{Creating “Good Enough” Practice}

In order to move the stalled project forward, the project team had to make a choice between creating a system that would work for Ivy, and sticking to their so-called gold standard. The team chose the former and began to appropriate a local solution from best practice rhetoric. The notion of IS appropriation, previously considered as the relatively static final phase of development (Collins 1993), is seen as being more dynamic in nature (Pan et al. 2003; Robertson et al. 1996). This study supports the latter interpretation by illustrating appropriation of a system, not as a one-time event of achieving order, but rather as an iterative process where order is achieved, controversy accommodated, and relative stability regained over time.

The value of extending the analysis beyond the installation of the best practice system is that we focus on achievement itself as a unit of analysis. Our study of successive inscriptions of interests into the Ivy-Vision ERP development provided a partial history of what circulated within the ontological network of project members. This provided insights into what it meant to be connected or disconnected from Ivy's socio-technical ensemble. However, by following the processes of achieving such inscriptions, we are able to report on the properties that were gained as well as those that were lost in each phase of transformation. We saw that the creation of an installed base contributed to shaping Ivy's organizational future; the ERP environment is hard for users to reject completely, but the achievement of order that has emerged from the ERP project is temporary and partial. The functionality that had been lost in the design of the installed base was later found to be a key actor in maintaining the enrolment of Ivy actors in the ERP-enabled environment. The longitudinal nature of this study enabled us to analyze how Ivy managed to move forward in spite of the complications that accompanied the project team's appropriation of best practice.

Ivy's appropriation of the ERP system was achieved through compromise. The investment made it difficult to reject the software outright. However, when the project team attempted to align the wider Ivy community with the system, they aggravated many socio-technical arrangements that had constituted Ivy's very existence. In seeking to align faculty with a business storyline, the team were faced with a further round of negotiations, enrolments, and translations of interest, which ironically produced, not alignment, but another reconfiguration of best practice. 
Debates surrounding legacy accounting versus corporate best practice dominated shaping Ivy's future. The question to be answered was not just about whose stories would be recognized but also whose perspectives would inform and guide the financial management of faculty dollars. By following the processes of inscription, we learn about the system properties that are gained as well as those that are lost in each phase of transformation. This provides insights into what it means to be connected or disconnected from a socio-technical ensemble. An actor-network analysis provided insight into Ivy's struggle to answer these questions. Our findings not only illuminate the process by which the relative value of potential best practices are debated, but also the way specific actor-networks can shape negotiation. We recall the quotation by a technical team leader who proposed that Ivy actors without plausible and forwardfocused stories were excluded from the "narrow universe of people included in the consensus picture." However, we saw actors being included in negotiations without wholly subscribing to the dominant vision.

The creation of design modifications and TSC illustrate how appropriation can be achieved despite consensus. Actors can coordinate without always having to share the same epistemological position. However, actors whose narratives speak only of the past are trying to combat the irreversible arrow of time (Adam 1995) that pushes us forward. As such, these actors do not provide a plausible narrative that can be translated into the future. Their stories cannot be considered equal to others. The effect is that they become silenced because of their irrelevance to the negotiations occurring within the change initiative. We were able to access some of these stories but we found that their interests failed to be designed into IT artifacts because they were unconnected to the network alliances shaping Ivy's future.

\subsection{Theorizing the IT Artifact}

The choice of a narrative research approach, used to apply ANT, arose from our interest in analyzing the adoption and use of best practices over time. Our findings show that these black-boxed practices get deconstructed through use. They are then reconstructed and take on a hybrid form; the prescribed, generic processes become infused with local value. The study of technology-in-use is a timely topic because it directly contributes to a broad discussion about the lack of research within IS that theorizes the IT artifact (Benbasat and Zmud 2003; Orlikowski and Iocono 2001; Weber 2003). This gap is especially problematic for IFIP WG 8.2 because of participant interest in the "relationships and interactions between information systems, information technology, organizations and society" (Fitzgerald et al. 1985).

Our challenge is to cultivate research that adopts an "ensemble view of technology focused on the interplay between people and technology" (Orlikowski and Iacono 2001, p. 126). The current ensemble view literature is categorized as either concentrating on how technologies come to $\boldsymbol{b} \boldsymbol{e}$ in the historical style of actor-network theoreticians, or on how technologies come to be used (ibid). Here, we build on these ideas by not separating how technologies come to be or be used. Instead, we interpret the process of technology development and its subsequent appropriation as continuous and situated in time. The narrative application of ANT allows researchers to follow the continuous 
evolution of technologies as they come to be defined as working IS-accepted and used. This is in keeping with Benbasat and Zmud's (2003) call for research that focuses on the relationships between the IT artifact, its use, and its impact on practices and capabilities.

As more organizations either partner with vendors to modify software in an attempt to create best practice products for their industry sector, or adopt such software based on these claims, it is important for us to analyze, theorize, and translate to practitioners the implications of such initiatives. The socio-technical ensemble view of technology is one that is gaining legitimacy within the business community (Schrage 2003; Schweisberger and Chatterjee 2002). However, the notion is black-boxed itself, providing a convenient way of talking about complex systems. We concentrate here on ways that we can understand and guide negotiations, and the inscription of interests into artifacts. It is not just that new interests are designed into software, rather it is that new and old comingle, that history informs the present and can shape the future. We argue that the combination of narrative and ANT provides distinctive insights into this process, and promising tools for studying the interplay between humans and nonhumans in particular contexts.

\subsection{Reflections on Method}

We suggest that one way to respond to the need to theorize the IT artifact is to echo Pettigrew's (1985) call for longitudinal research, in this instance focusing on phased field visits in order to yield insights on how technologies are introduced, shaped, and reshaped over time, and with what organizational consequences. This might be accomplished by focusing on the dynamics of IT-enabled change processes, rather than making hard and fast statements based on findings from a particular phase of the project. Robertson et al. (1996) use a model of different IT project phases to understand the influence of suppliers and organizational stakeholders in the diffusion and appropriation of software products sold as best practice solutions. Their analysis emphasizes the influence that these phases had on preceding and subsequent negotiations involved in appropriating software. The field work design of this study was aimed at analyzing the dynamics of IT-enabled change itself rather than a particular outcome.

narrative...as the central organizing principal of the research, draws on multiple stories clustered around negotiation to help the researcher follow emergent action and study the interconnections between people and technology over time (Wagner 2003).

Such methodological tools are employed to remind us that the primary goal is to understand a

longitudinal sequence of drama that allows varying readings to be taken of the development of the organizational information system, of the impact of one drama on successive and even consequent dramas, and of the kinds of mechanisms that lead to, accentuate, and regulate the impact of each drama (Pettigrew 1990, p. 275). 
In recognition of the multiple influences revealed in this study, its context is organized around the transformation of an Ivy community that is continually being reformed through the stories, negotiations, and actions of its actors. Further, Ivy is made durable through the design and modification of its material objects, software, work procedures, and structures (Latour 1991).

\subsection{Limitations and Contributions}

We suggest that creating an IS that is accepted as a matter of fact by constituent actors is more likely when its design takes into account valued legacy practices and incorporates the past into best practice designs. We argue that the likelihood of a system being appropriated within an organization increases when there is continuity between the legacy environment and proposed future activities. This is fundamentally at odds with the best practice agenda. Vision's system failed to be accepted as a matter of fact because its accounting module ignored the grand narrative that had informed Ivy practice over many years. Vision's best practice accounting functionality was informed by a corporate business logic that ignored budgeting and grants management activities in universities. Appropriating the accounting functionality was difficult to achieve because administrative tasks involved multiple interest groups whose views differed dramatically. This suggests that integration cannot always be achieved by mandating a standard view to which all actors must subscribe.

The analysis of the post-installation customization of Ivy's best practice system suggests that integration is better understood as a process of selectively negotiating in order to create a good enough solution that meets multiple and interpenetrating needs. The analysis of boundary objects shows the relevance of local practice in IS design. It would appear that a future vision should enroll actors, but so too should negotiators consider what works for the organization, based on past activities and current imperatives.

Process-oriented researchers will know how difficult it is to take background assumptions of ANT and narrative and apply it in the field. We provide four key points that helped us study IT change in an ANT-narrative mode. The first relates to extending the notion of agency to both human and nonhuman actors. This is in order to follow action as it unfolds without specifying in advance who or what participates in negotiations. Next, it is important to recognize that we begin our research of IT-enabled change at a particular moment in the organization's history where the future is being planned for and negotiated. A network is formed that connects the interests of multiple actors. This network is constituted by the relationships between actors and indicates that other groups are being dismantled as a result of this enrolment. Third, we do not set $a$ priori boundaries on the scope of the research context. Finally, our notion of IT-enabled change as an achievement of order is fundamental to an ANT-narrative approach (Monteiro 2000). Conceptualizing order as a temporary state emphasizes multiple agencies of change and order, providing a nonlinear account of negotiation.

\subsection{Future Research and Unanswered Questions}

We argue that over time the best practice trend will be diluted as organizations implement inflexible software-based standards and find them problematic. We question 
the notion of best practices as synonymous with relinquishment of valued legacy work practices. We consider what stories concerning the ERP system were brought forward from the best practice design only to be later overwritten by customization efforts. One area for future research would be to consider the extent of a potential backlash to the ERP trend as a result of its best business practice design.

The Ivy-Vision ERP package is currently being sold as inscribing best practices for universities globally. As people try to apply these practices to local situations, and as circumstances change, we argue that they will begin to evaluate the extent to which local practices are of greater value than those mandated by best practice. Such a choice was adopted by Ivy but not without a price. It would be interesting to consider the extent to which the best practice concept is storing up trouble for software providers, and to critically evaluate outsourcing strategies and application service provision agreements.

\section{REFERENCES}

Adam, B. Timewatch: The Social Analysis of Time, Cambridge: Polity Press Ltd, 1995.

Akrich, M., and Latour, B. "A Summary of Convenient Vocabulary for the Semiotics of Human and Nonhuman Assemblies," in W. E. Bijker and J. Law (Eds.), Shaping Technology/ Building Society, Cambridge, MA: MIT Press, 1992, pp. 259-264.

Atkins, C., and Louw, G. "Reclaiming Knowledge: A Case for Evidence-Based Information Systems," in H. Hansen, M. Bichler, and H. Mahrer (Eds.), Proceedings of the $\mathbf{8}^{\text {th }}$ European Conference on Information Systems, Vienna, Austria, 2000, pp. 39-45.

Benbasat, I., and Zmud, R. W. "The Identity Crisis Wwithin the IS Discipline: Defining and Communicating the Discipline's Core Properties," MIS Quarterly (27:2), 2003, pp. 183-194.

Bowker, G., and Star, S. L. Sorting Things Out: Classification and its Consequences, London: MIT Press, 1999.

Bruner, J. S. Acts of Meaning, Cambridge, MA: Harvard University Press, 1990.

Callon, M. "Some Elements of a Sociology of Translation: Domestication of the Scallops and the Fishermen of St. Brieuc Bay," in J. Law (Ed.), Power, Action and Belief: A New Sociology of Knowledge?, London: Routledge \& Kegan Paul, 1986, pp. 196-231.

Collins, H. M. "The Structure of Knowledge," Social Research (60), 1993, pp. 95-116.

Collins, H. M., and Yearley, S. "Journey into Space," in A. Pickering (Ed.), Science as Practice and Culture, Chicago: University of Chicago Press, 1992.

Cortada, J. W. Best Practices in Information Technology : How Corporations Get the Most Value from Exploiting Their Digital Investments, Upper Saddle River, NJ: Prentice Hall, 1998.

Cragg, P. "Benchmarking Information Technology Practices in Small Firms," European Journal of Information Systems (11), 2002, pp. 267-282.

Czarniawska, B. A Narrative Approach to Organization Studies. Volume 43 Qualitative Research Methods, London: Sage Publications Inc., 1998.

Davenport, T. H. Mission Critical: Realizing the Promise of Enterprise Systems, Boston: Harvard Business School Press, 2000.

Fitzgerald, G.; Hirschheim, R. A.; Mumford, E.; and Wood-Harper, A. T. "Information Systems Research Methodology: An Introduction to the Debate," in E. Mumford, R. Hirschheim, G. Fitzgerald, and A. T. Wood-Harper (Eds.), Research Methods in Information Systems, Amsterdam: North-Holland, 1985.

Fujimura, J. H. "Crafting Science: Standardized Packages, Boundary Objects, 'Translation'," in A. Pickering (Ed.), Science as Practice and Culture, Chicago: Chicago University Press, 1992, pp. 168-211. 
Hanseth, O. "The Economics of Standards," in C. Ciborra and Associates (Eds.), From Control to Drift: The Dynamics of Corporate Information Infrastructures, Oxford: Oxford University Press, 2000, pp. 56-70.

Hanseth, O., and Braa, K. "Hunting for the Treasure at the End of the Rainbow: Standardizing Corporate IT Infrastructure," in O. Ngwenyama, L. Introna, M. D. Myers, and J. I. DeGross (Eds.), New Information Technologies in Organizational Processes: Field Studies and Theoretical Reflections on the Future of Work, London: Chapman \& Hall, 1999, 121-140.

Hanseth, O., and Braa, K. "Technology as Traitor: SAP Infrastructure in Global Organizations," in R. Hirschheim, M. Newman, and J. I. DeGross (Eds.), Proceedings of the $19^{\text {th }}$ International Conference on Information Systems. Helsinki, Finland, 1998,pp. 188-196.

Kremers, M., and van Dissel, H. "ERP System Migrations," Communications of the ACM(43:4), 2000, pp. 53-56.

Kumar, K., and Van Hillegersberg, J. "ERP Experiences and Evolution," Communications of the ACM (43:4), 2000, pp. 23-26.

Latour, B. Pandora's Hope: Essays on the Reality of Science Studies, Cambridge, MA: Harvard University Press, 1999.

Latour, B. Science in Action: How to Follow Scientists and Engineers through Society, Cambridge, MA: Harvard University Press, 1987.

Latour, B. "Technology is Society Made Durable," in J. Law (Ed.), A Sociology of Monsters: Essays on Power, Technology and Domination, London: Routledge, 1991, pp. 103-131.

Law, J. "After ANT: Complexity, Naming and Topology," in J. Law and J. Hassard (Eds.), Actor Network Theory and After, Oxford: Blackwell Publishers, 1999, pp. 15-25.

Monteiro, E. "Actor-Network Theory," in C. Ciborra and Associates (Eds.), From Control to Drift: The Dynamics of Corporate Information Infrastructures, Oxford: Oxford University Press, 2000.

Newell, S., Swan, J., and Galliers, R. D. "A Knowledge-Focused Perspective on the Diffusion and Adoption of Complex Information Technologies: The BPR Example," Information Systems Journal (10), 2000, pp. 239-259.

Noble, D. F. "Digital Diploma Mills: The Automation of Higher Education," First Monday (3:1), 1998.

Orlikowski, W. J., and Iacono, C. S. "Research Commentary: Desperately Seeking the 'IT' in IT Research-A Call to Theorizing the IT Artifact," Information Systems Research (12:2), Number 2, 2001, pp. 121-134.

Pan, S. L.; Newell, S.; Galliers, R. D.; and Huang, J. "Overcoming Knowledge Integration Challenges During ERP Adoption: The Role of Social Capital," under review, 2003.

Pettigrew, A. M. "Contextualist Research: A Natural Way to Link Theory and Practice," in E. Lawler (Ed.), Doing Research That Is Useful in Theory and Practice, San Francisco: Jossey-Bass, 1985, pp. 222-249.

Pettigrew, A. M. "Longitudinal Field Research on Change: Theory and Practice," Organization Science (1:3), 1990, pp. 267-291.

Robertson, M.; Swan, J.; and Newell, S. "The Role of Networks in the Diffusion of Technological Innovation," Journal of Management Studies (33:3), 1996, pp. 333-359.

Sawyer, S. "A Market-Based Perspective on Information Systems Development," Communications of the ACM (44:11), 2001, pp. 97-102.

Schrage, M. "Why IT Really Does Matter," CIO Magazine, August 1, 2003 (available online at http://www.cio.com/archive/080103/work.html).

Schweisberger, J., and Chatterjee, A. "Effective CRM Implementations," Hospitality Upgrade, 2002 (available online at www.hospitalityupgrade.com/).

Scott, S. V. "IT-Enabled Credit Risk Modernization: A Revolution Under the Cloak of Normality," Accounting, Management and Information Technologies (10:3), 2000, pp. 221-255. 
Scott, S. V., and Wagner, E. L. "Networks, Negotiations, and New Times: The Implementation of Enterprise Resource Planning into an Academic Administration," Information and Organization (13:4), 2003, pp. 285-313.

Star, S. L., and Griesemer, J. R. "Institutional Ecology, 'Translations' and Boundary Objects: Amateurs and Professionals in Berkeley's Museum of Vertebrate Zoology, 1909-39," Social Studies of Science (19), 1989, pp. 387-420.

Swan, J.; Newell, S.; and Robertson, M. "The Illusion of 'Best Practice' in Information Systems for Operations Management," European Journal of Information Systems (8), 1999, pp. 284293.

Timbrell, G.; Andrews, N.; and Gable, G. "Impediments to Inter-Firm Transfer of Best Practice: In an Enterprise Systems Context," Australian Journal of Information Systems, Special Edition, 2001, pp. 116-125.

Wagner, E. L. "Interconnecting Information Systems Narrative Research: Current Status and Future Opportunities for Process-Oriented Field Studies," in E. Wynn, E. A. Whitley, M. Myers, and J. I. DeGross (Edsl;), Global and Organizational Discourse About Information Technology, Boston: Kluwer Academic Publishers, 2003, pp. 419-436.

Walsham, G. Interpreting Information Systems in Organizations, Chichester, England: Wiley, 1993.

Walsham, G. Making a World of Difference: IT in a Global Context, Chichester: John Wiley and Sons, 2001.

Walsham, G., and Sahay, S. "GIS for District-Level Administration in India: Problems and Opportunities," MIS Quarterly (23:1), 1999, pp. 39-65.

Weber, R. "Editor's Comments: Still Desperately Seeking the IT Artifact," MIS Quarterly (27:2), 2003, pp. iii-xi.

\section{ABOUT THE AUTHORS}

Erica L. Wagner is an assistant professor of Information Systems at Cornell University's School of Hotel Administration. She is trained as an accountant and social scientist, and recently completing her Ph.D. (2002) at the London School of Economics, University of London. Her research centers on the ways in which information and communication technologies (ICT) are made to work within different organizational contexts. As a qualitative field researcher, she attempts to emphasize how negotiating with technology necessarily implies the reordering of organizational reality through design, implementation, and customisation activities. Erica can be reached by email at elw32@cornell.edu.

Robert D Galliers is the Provost of Bentley College and was previously Professor of Information Systems and Research Director in the Department of Information Systems at the London School of Economics (LSE). Before joining LSE, he served as Professor and Dean of Warwick Business School in the UK, and earlier as Professor and Head of the School of Information Systems at Curtin University in Australia. He has a Ph.D. from the LSE and an Honorary D.Sc. from Turku School of Economics \& Business Administration, Finland. A leader in the field of management information systems, he is editor-in-chief of the Journal of Strategic Information Systems, and a fellow of the Association for Information Systems (AIS), the British Computer Society, and the Royal Society of Arts. He is past president of the AIS and was program cochair of the 2002 International Conference on Information Systems. He has held visiting professorships at INSEAD, France, University of St Gallen, Switzerland, City University of Hong Kong, the Institute for Advanced Management Studies, Belgium, National University of Singapore, Hong Kong Polytechnic University, and Bond University, Australia. He has published widely in leading international IS journals and has also authored/edited a number ofbooks, the most recent being the third edition of the best seller Strategic Information Management (Butterworth- 
Heinemann, 2003), with Dorothy Leidner; Rethinking Management Information Systems (Oxford University Press, 1999) with Wendy Currie, and IT and Organizational Transformation (Wiley, 1998) with Walter Baets. Bob can be reached at galliers@LNMTA.bentley.edu.

Susan Scott is a lecturer in the Information Systems Department at the London School of Economics where she pursues research focusing of the role of information systems in the transformation of financial services. She is Academic Director of the Moving Markets research project and teaches courses on IS in Business. Her background includes degrees in African History and Politics (SOAS), Analysis, Design and Management of Information Systems (LSE), and a Ph.D. in Management (Cambridge). Susan can be reached at S.V.Scott@lse.ac.uk. 